\title{
Sitagliptin as an Initial Therapy and Differential Regulations of Metabolic Parameters Depending on its Glycemic Response in Subjects with Type 2 Diabetes
}

Authors

Eiji Kutoh ${ }^{1,2,3}$, Alexandra N. Kutoํ․, Askuka Wada², Jyunka Hayashi², Rumi Kurihara²

\author{
Affiliations \\ 1 Biomedical Center, Tokyo, Japan \\ 2 Division of Diabetes and Endocrinology, Department of \\ Internal Medicine, Gyoda General Hospital, Saitama, Japan \\ 3 Division of Diabetes and Metabolism, Department of \\ Internal Medicine, Higashitotsuka Memorial Hospital, \\ Yokohama, Japan
}

\section{Key words}

antidiabetic drugs, drug research, lipid-lowering drugs, metabolic pharmacology, pharmaceutics

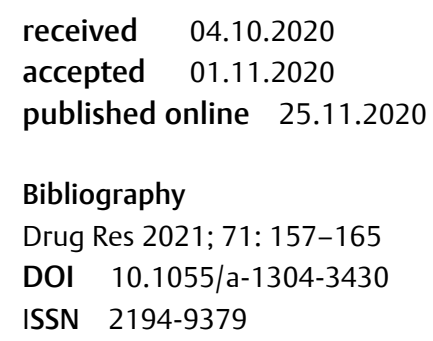

ekuto@excite.com, ekuto-biomed@umin.ac.jp

\begin{abstract}
The aim of this study is to investigate whether sitagliptin can be used as an initial drug for T2DM and to evaluate its effects on metabolic parameters in relation to its glycemic efficacies. The subjects received $25-50 \mathrm{mg}$ /day sitagliptin monotherapy $(n=69)$. At 3 months, they were divided into three groups ( $n=23$ each) according to the novel parameter called "A1c index" which is designed to assess glycemic efficacy. The metabolic parameters were compared between good-responders and poor-responders. These two groups acted as a control each other. In the overall subjects, efficient reductions of HbA1c (10.16-8.22\%) were observed with few adverse events. Significant correlations were seen between the $A 1 C$ index and changes of $(\Delta)$ nonHDL-C $(R=0.250)$ or $\triangle \mathrm{LDL}-\mathrm{C}(\mathrm{R}=0.368)$. At baseline, T-C, nonHDL-C and BMI levels were significantly lower in good-responders than poor-responders. At 3 months, in good-responders, HbA1c levels effectively decreased (11.03$7.00 \%$ ). Indexes for insulin sensitivity/resistance [HOMA-R and 20/(C-peptide x FBG)] and beta-cell function (HOMA-B and CPR-index) ameliorated. T-C, nonHDL-C and LDL-C significantly decreased, while BMI increased. However, in poor-responders, no changes in these parameters were noted. Collectively, these results suggest that 1) Sitagliptin can be used as a firstline drug for T2DM and its glycemic efficacy is linked to some atherogenic lipids. 2) Those with lower T-C, nonHDL-C and BMI appear to respond better with this drug. 3) Good glycemic efficacy of sitagliptin is medicated through reduced insulin resistance as well as enhanced beta-cell functions. Body weight increased, while some atherogenic cholesterol decreased in good-responders.
\end{abstract}

$\begin{array}{ll}\text { ABBREVIATION } \\ \text { T2DM } & \text { type } 2 \text { diabetes } \\ \text { FBG } & \text { fasting blood glucose } \\ \text { HOMA-R } & \text { homeostasis model assessment-R } \\ \text { HOMA-B } & \text { homeostasis model assessment-B } \\ \text { T-C } & \text { total cholesterol }\end{array}$

TG triglyceride

HDL-C high density lipoprotein cholesterol

LDL-C low density lipoprotein cholesterol

BMI body mass index 


\section{Introduction}

Healthy diet, physical exercise and weight management are initial methods to treat newly diagnosed T2DM, however, the increasing prevalence of T2DM worldwide strongly indicates that these strategies are important but not sufficient to control this disease. T2DM is still in need of effective treatments that have a long-term impact on the course of the disease and its associated complications. The 2020 American Diabetes Association's Standards of Medical Care in Diabetes states that the first-line pharmacotherapy of T2DM diabetes is metformin [1]. However, other drugs could be candidates as well in some circumstances. For example, in patients where metformin is contraindicated (advanced heart failure, chronic kidney disease), and/or in those who have tolerability problems or adverse events with metformin (e. g. gastrointestinal problems, diarrhea).

Dipeptidyl peptidase-4 (DPP-4) inhibitors have been available for more than a decade in the actual clinical practice. They have good glycemic efficacies with low risk of adverse events such as hypoglycemia and weight gain, and with overall good tolerability profiles [2,3]. They have been shown to enhance beta-cell function and insulin secretory capacity, thus they may be appropriate in the early stage of the disease when the patients still possess certain levels of beta-cell function $[4,5]$. Sitagliptin is the first and most widely used drug in this class throughout the world [6, 7]. Although sitagliptin has been convincingly shown to have efficient glycemic properties, other effects on non-glycemic parameters, for example, insulin sensitivity, lipid and body weight remain controversial [8-10]. Further, it remains to be investigated whether this drug could be used as an initial therapy for T2DM.

To investigate these questions, sitagliptin $25-50 \mathrm{mg} /$ day monotherapy was performed in newly diagnosed, drug naïve subjects with T2DM and the effects on several glycemic and non-glycemic parameters were monitored. Defining responders to glucose lowering therapy is important for diabetes therapy. Response to glucose lowering therapy is usually, conventionally defined by the absolute change in HbA1c levels. However, this method can be a concern, since it is well known that the baseline HbA1c level strongly influences response to glucose lowering therapies [9, 11]. Many studies which are designed to identify predictors of glycemic response do not adjust for baseline HbA1c levels. Thus, this may contribute to marked variations in the findings of these studies. To overcome this problem, in the past several years, we used $A 1 \mathrm{c}$ index where the changes of $(\triangle) \mathrm{HbA} 1 \mathrm{c}$ were adjusted by the baseline HbA1c levels ( $\triangle \mathrm{HbA} 1 \mathrm{c} /$ baseline HbA1c; $[9,11])$. Using this A1c index, the subjects were divided into 3 equal numbers of subjects (good-, intermediate- and poor-responders) in order to avoid any bias for the division of the group. The glycemic and non-glycemic parameters were compared between good-responders (lowest tertile of A1C index) and poor-responders (highest tertile of A1C index).

\section{Subjects and Methods}

\section{Subjects}

Currently our group has a project of investigating new oral hypoglycemic drugs as an initial therapy in drug naïve subjects with
T2DM. The subjects are either newly diagnosed or previously diagnosed but untreated. Inclusion and exclusion criteria were described previously $[9,11]$. The subjects were recruited from the outpatient department of Internal Medicine of Gyoda General Hospital and other associated hospitals. The subjects (initially stared with 76 subjects) received $25 \mathrm{mg} /$ day (for female, $\mathrm{n}=18$ ) or $50 \mathrm{mg} /$ day (for male, $n=58$ ) sitagliptin monotherapy. No other drugs were administered during the study. The subjects were encouraged to follow exercise and diet as described $[9,11]$. Informed consents were obtained from the patients and the protocol of this study was approved by the investigational review board (IRB) of Gyoda General Hospital. This study was conducted in accordance with principles of Good Clinical Practice. The subjects were informed they were free to leave the therapy whenever they wished. 2 subjects dropped out due to intolerability and/or potential adverse events. 5 subjects just stopped visiting the hospital without any reasons.

\section{Laboratory measurements}

The primary end point was the change of $\mathrm{HbA} 1 \mathrm{c}$ levels from baseline to 3 months. All the subjects had $\mathrm{HbA} 1 \mathrm{c}>7 \%$ at baseline. The secondary end-points were the changes of fasting blood glucose (FBG) and other metabolic parameters including insulin, HOMA-R, HOMA-B, C-peptide, CPR-index, 20/(C-peptide x FBG), total cholesterol (T-C), triglyceride (TG), high density lipoprotein cholesterol (HDL-C), nonHDL-C, low density lipopreotein (LDL-C), T-C/HDL-C, nonHDL-C/HDL-C, uric acid (UA) and BMI from baseline to 3 months. Blood was collected in the fasting state in the morning hours. Measurements of $\mathrm{HbA} 1 \mathrm{C}$ and $\mathrm{FBG}$ were performed once a month. T-C, TG, HDL-C, LDL-C, UA, insulin and C-peptide were measured using standard techniques as described previously [9] at the start (baseline) and at the end (3 months) of the study. Anti-glutamic acid decarboxylase (GAD) antibody was measured in some suspected patients in order to exclude those with T1DM (Mitsubishi LSI or BML, Tokyo, Japan). HOMA-R, HOMA-B, CPR-index and 20/(C-peptide $\times$ FBG) were calculated as described $[9,12]$. Liver (AST: aspartate amino transferase, ALT: amino alanine transferase, ALP: alkaline phosphatase, and $\gamma$-GTP; gamma glutamyl transpeptidase) and renal (BUN: blood urea nitrogen and CRE: creatinine) functions were also monitored monthly. In the case of any significant increase in these parameters or other adverse events, administration of sitagliptin was planned to discontinue. The drop-out subjects were excluded from data analysis.

Adjustments of the changes in $\mathrm{HbA} 1 \mathrm{c}$ levels ( $\triangle \mathrm{HbA} 1 \mathrm{c}$ ) by its baseline levels ( $\triangle \mathrm{HbA} 1 \mathrm{c} /$ baseline $\mathrm{HbA} 1 \mathrm{c}$ ), defined as "A1c index" were performed $[9,11]$. The subjects were divided into three groups with equal numbers of subjects ( $n=23$ each) according to the A1c index.

good responders: $-0.3562 \pm 0.1006$ (lowest tertile)

intermediate responders: $-0.1542 \pm 0.0431$ (intermediate tertile)

poor responders: $-0.0357 \pm 0.0682$ (highest tertile)

\section{Data analyses}

Descriptive statistics for all the parameters studied included the mean changes from baseline to 3 months. Unpaired Student's t-test was used to analyze the difference at baseline between two subgroups (good-responders and poor-responders). When the data 
were normally distributed, paired Student's t-test was used to analyze the changes in each group (intra-group differences). When the data were not normally distributed, Wilcoxon signed-rank test was employed. An analysis of covariance (ANCOVA) was used to analyze the inter-group differences. Simple regression analysis was performed to analyze the correlations between the A1c index and other parameters (baseline and changes). The results were expressed as the mean + SD. The statistical analysis was undertaken using the PAST program from the University of Oslo (https://folk. uio.no/ohammer/past/). Throughout the statistical analysis, values of $p<0.05$ were considered significant. Values of $0.05<p<0.1$ were considered statistically insignificant but determined to show a tendency to potential differences or correlations [13].

\section{Results}

\section{Safety and tolerability (overall subjects)}

2 out of 71 subjects (both women) reported mild, potential hypoglycemic events, (though not confirmed by actually measuring blood glucose levels), which could be easily managed by taking sugar containing candies or drinks by themselves. One female subject reported mild constipation and fullness of abdomen. These potential adverse events occurred in the first 4 weeks of the initiation of the drug. Otherwise no subjects had any clinically significant elevations of renal or hepatic enzymes. 2 subjects (one with potential hypoglycemic events and another with constipation/fullness of abdomen) had dropped out because of intolerance or adverse events.

\section{Effect of sitagliptin on glycemic related parameters (overall subjects)}

At 3 months with sitagliptin treatment, effective reductions of HbA1c (from 10.16 + 2.17 to 8.22 + 2.14\%) and FBG ( $-11.7 \%$ ) were observed (for each value and statistical significance, see $\triangleright$ Table 1). 27 out of 69 subjects achieved $\mathrm{HbA} 1 \mathrm{c}<7 \%$. Significant correlations were observed between the changes of $(\Delta) \mathrm{HbA} 1 \mathrm{c}$ and the baseline HbA1c ( Fig. 1a). By contrast, no correlations were noted between the changes of $(\triangle)$ FBG and the baseline FBG ( $>$ Fig. 1b). Significant increases of insulin (13.5\%), HOMA-B ( + 53.3\%), C-peptide (8\%), [20/(C-peptide × FBG), $19.8 \%$ ] and CPR-index (27.8 \%) were seen.

Significant negative correlations were observed between the A1C index and the baseline levels of CPR-index $(R=-0.245$, $>$ Table 2 panel a). Significant correlations were seen between the $A 1 c$ index and the changes of $(\Delta)$ FBG $(R=0.642)$ or $\triangle H b A 1 c(R=0.966)$, and significant negative correlations were observed between the $A 1 C$ index and $\Delta[20 /(C$-peptide $x$ FBG $), R=-0.296), \triangle$ HOMA-B $(R=-0.575)$ or $\triangle C P R$-index $(R=-0.641$, $>$ Table 2 panel $b)$.

\section{Effect of sitagliptin on non-glycemic parameters (overall subjects)}

At 3 months with sitagliptin treatment, T-C ( $-2.8 \%)$, T-C/HDL-C ( $-3.5 \%)$, nonHDL-C ( $-4.0 \%)$ and nonHDL-C/HDL-C $(-4.6 \%)$ significantly decreased while other parameters including TG, HDL-C or LDL-C had no changes ( $\triangleright$ Table 1 ). Significant increases of UA $(+9.2 \%)$ and insignificant increases of BMI (1\%) were observed ( $\triangleright$ Table 1). Blood pressure was also monitored, however, the variations were so large and no conclusions have been made regarding the effect of sitagliptin on blood pressure (results not shown).

- Table 1 Changes of glycemic and non-glycemic parameters after 3 months treatment with sitagliptin.

\begin{tabular}{|c|c|c|c|c|}
\hline & baseline & 3 months & p-values & \% changes \\
\hline age (years) & $55.3 \pm 12.7$ & & & \\
\hline $\mathrm{F} / \mathrm{M}$ & $15 / 54$ & & & \\
\hline A1c index & $-0.1820 \pm 0.1521$ & & & \\
\hline FBG (mg/dl) & $216.3 \pm 65.8$ & $190.8 \pm 76.2$ & $<0.0007$ & -11.7 \\
\hline $\mathrm{HbA1c}(\%)$ & $10.16 \pm 2.17$ & $8.22 \pm 2.14$ & $<0.00001$ & -19 \\
\hline insulin $(\mu \mathrm{U} / \mathrm{ml})$ & $6.66 \pm 4.21$ & $7.56 \pm 5.67$ & $<0.05$ & 13.5 \\
\hline HOMA-R & $3.50 \pm 2.58$ & $3.65 \pm 3.70$ & n.s. & 4.2 \\
\hline HOMA-B & $19.76 \pm 16.40$ & $30.31 \pm 33.43$ & $<0.002$ & 53.3 \\
\hline C-peptide (ng/ml) & $1.98 \pm 0.90$ & $2.14 \pm 1.08$ & $<0.008$ & 8 \\
\hline 20/(C-pepide x FBG) & $0.0644 \pm 0.0425$ & $0.0772 \pm 0.0686$ & $<0.03$ & 19.8 \\
\hline CPR-index & $0.997 \pm 0.537$ & $1.275 \pm 0.755$ & $<0.00001$ & 27.8 \\
\hline $\mathrm{T}-\mathrm{C}(\mathrm{mg} / \mathrm{dl})$ & $226.2 \pm 41.6$ & $219.8 \pm 39.8$ & $<0.05$ & -2.8 \\
\hline TG (mg/dl) & $196.0 \pm 181.9$ & $184.4 \pm 150.5$ & n.s. & -5.9 \\
\hline HDL-C (mg/dl) & $55.8 \pm 15.0$ & $56.3 \pm 15.3$ & n.s. & 0.8 \\
\hline $\mathrm{T}-\mathrm{C} / \mathrm{HDL}-\mathrm{C}$ & $4.26 \pm 1.17$ & $4.11 \pm 1.15$ & $<0.05$ & -3.5 \\
\hline nonHDL-C (mg/dl) & $170.4 \pm 41.8$ & $163.5 \pm 39.4$ & $<0.02$ & -4 \\
\hline nonHDL-C/HDL-C & $3.26 \pm 1.17$ & $3.11 \pm 1.15$ & $<0.05$ & -4.6 \\
\hline LDL-C (mg/dl) & $144.2 \pm 32.7$ & $140.9 \pm 35.0$ & n.s. & -2.2 \\
\hline UA (mg/dl) & $4.98 \pm 1.28$ & $5.44 \pm 1.40$ & $<0.00001$ & 9.2 \\
\hline BMI & $24.66 \pm 4.35$ & $24.92 \pm 4.34$ & 0.059 & 1 \\
\hline
\end{tabular}

Paired Student's t-test was used to compare the changes of the indicated parameters before and after 3 months treatment. The results are expressed as the mean \pm SD. 

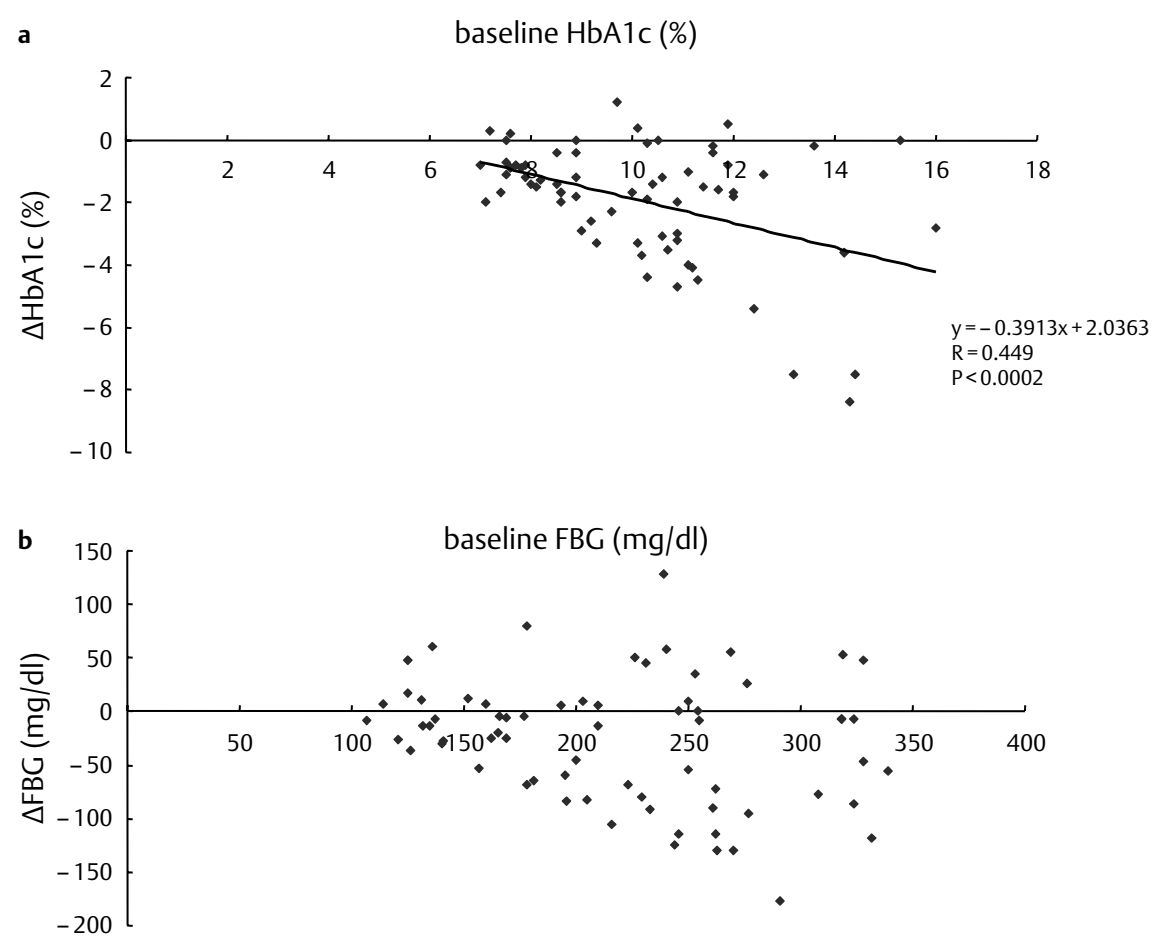

- Fig. 1 Baseline-dependent glycemic efficacies of sitagliptin. Simple regression analysis was performed between the changes of $(\triangle)$ HbA1c/FBG and baseline HbA1c/FBG levels. a HbA1c. b FBG.

Significant correlations were observed between the A1C index and the baseline levels of $\mathrm{T}-\mathrm{C}(\mathrm{R}=0.246$, $>$ Table 2a). Significant correlations were seen between the $A 1 C$ index and the changes of $(\Delta)$ nonHDL-C $(R=0.250)$ or $\triangle L D L-C(R=0.368)$, and significant negative correlations were observed between the $A 1 \mathrm{c}$ index and $\triangle \mathrm{UA}(\mathrm{R}=-0.239)$ or $\triangle \mathrm{BMI}(\mathrm{R}=-0.269$, $>$ Table 2 panel $\mathrm{b})$.

\section{Differential regulation of glycemic and non-glycemic parameters between good-responders and poor responders with sitagliptin}

At baseline ( $\triangleright$ Table 3), T-C, non-HDL-C and BMI levels were significantly lower in good-responders than poor-responders. HbA1c had a tendency to be higher and TG lower in good-responders than poor-responders. Other parameters showed no statistically significant differences between these two groups. As shown in > Table 4 (panel a, b and c), differential regulations of these parameters were observed.

\section{Good-responders ( $\triangleright$ Table 4 panel a)}

Both HbA1c (from $11.03+1.96 \%$ to $7.00+1.32 \%$ ) and FBG ( $-33.6 \%$ ) effectively, significantly decreased. HOMA-R ( $-29.9 \%)$ significantly decreased, while HOMA-B ( + 136.1\%) significantly increased. Both [20/(C-peptide x FBG), 49.3\%] and CPR-index (58.6\%) significantly increased. T-C ( $-5.3 \%), \mathrm{T}-\mathrm{C} / \mathrm{HDL}-\mathrm{C}(-8.6 \%)$, nonHDL-C (-8.2\%), nonHDL-C/HDL-C (-11.4\%) or LDL-C (-8.3\%) significantly decreased. UA (+10.3\%) and BMI (+2.1\%) significantly increased.
Poor-responders ( Table 4 panel b)

HbA1c (from $9.85+2.06 \%$ to $9.51+2.15 \%$ ) slightly but still significantly decreased, however, FBG had no changes. Significant increases of C-peptide (12.6\%), CPR-index ( $8.8 \%$ ) or UA ( $+6.7 \%$ ) were seen. No changes in other parameters were noted.

Intermediate-responders ( $\triangleright$ Table 4 panel c)

HbA1c (from $9.61+2.30 \%$ to $8.15+2.14 \%$ ) significantly deceased however, T-C $(-3.6 \%)$ and nonHDL-C $(-4.2 \%)$ had a tendency to decrease. UA (10.1\%) significantly increased. No changes in other parameters were noted.

Above data indicate that UA and CPR-index significantly increased, while HbA1c significantly decreased in either good-responders or poor-responders. With ANCOVA, significantly higher degrees of reductions of $\mathrm{HbA} 1 c(p<0.00001, \vee$ Fig. 2a), and elevations of CPR-index ( $p<0.00001$, > Fig. 2b) or UA ( $p<0.05$, - Fig. 2c) were seen in good-responders vs. poor-responders (inter-group differences).

\section{Discussion}

\section{Glycemic efficacies and safety of sitagliptin}

Baseline HbA1c levels of the subjects in this present study were rather high (above $10 \%$, > Table 1). However, this high HbA1c level is comparable to other studies undertaken with treatment naïve subjects with T2DM $[9,11]$. Patients with T2DM are usually asymp- 
- Table 2 Link between the A1c index and glyemic and non-glycemic parameters.

\begin{tabular}{|c|c|c|}
\hline \multicolumn{3}{|c|}{ Panel A: A1c index vs. baseline levels of the indicated parameters } \\
\hline A1c index vs. & $\mathbf{R}$ & p-values \\
\hline FBG & -0.215 & n.s. \\
\hline HbA1c & -0.156 & n.s. \\
\hline insulin & 0.043 & n.s. \\
\hline HOMA-R & 0.139 & n.s. \\
\hline HOMA-B & -0.104 & n.s. \\
\hline C-peptide & -0.142 & n.s. \\
\hline 20/(C-pepide ×FBG) & 0.078 & n.s. \\
\hline CPR-index & -0.245 & $<0.05$ \\
\hline $\mathrm{T}-\mathrm{C}$ & 0.246 & $<0.05$ \\
\hline TG & 0.159 & n.s. \\
\hline HDL-C & 0.112 & n.s. \\
\hline $\mathrm{T}-\mathrm{C} / \mathrm{HDL}-\mathrm{C}$ & 0.089 & n.s. \\
\hline nonHDL-C & 0.204 & n.s. \\
\hline nonHDL-C/HDL-C & 0.089 & n.s. \\
\hline LDL-C & 0.151 & n.s. \\
\hline UA & -0.117 & n.s. \\
\hline BMI & 0.085 & n.s. \\
\hline \multicolumn{3}{|c|}{ Panel B: A1c index vs. changes of $(\Delta)$ the indicated parameters } \\
\hline A1c index vs. & $\mathbf{R}$ & p-values \\
\hline$\triangle \mathrm{FBG}$ & 0.642 & $<0.00001$ \\
\hline$\triangle \mathrm{HbA} 1 \mathrm{c}$ & 0.966 & $<0.00001$ \\
\hline$\Delta$ insulin & -0.072 & n.s. \\
\hline$\triangle$ HOMA-R & 0.217 & 0.073 \\
\hline$\triangle \mathrm{HOMA}-\mathrm{B}$ & -0.575 & $<0.00001$ \\
\hline$\Delta C$-peptide & 0.139 & n.s. \\
\hline$\Delta 20 /($ C-pepide x FBG $)$ & -0.296 & $<0.02$ \\
\hline$\triangle C P R$-index & -0.641 & $<0.00001$ \\
\hline$\Delta \mathrm{T}-\mathrm{C}$ & 0.175 & n.s. \\
\hline$\triangle \mathrm{TG}$ & -0.029 & n.s. \\
\hline$\triangle \mathrm{HDL}-\mathrm{C}$ & 0.073 & n.s. \\
\hline$\triangle \mathrm{T}-\mathrm{C} / \mathrm{HDL}-\mathrm{C}$ & 0.167 & n.s. \\
\hline$\Delta$ nonHDL-C & 0.25 & $<0.05$ \\
\hline$\Delta$ nonHDL-C/HDL-C & 0.169 & n.s. \\
\hline$\Delta \mathrm{LDL}-\mathrm{C}$ & 0.368 & $<0.002$ \\
\hline$\Delta U A$ & -0.239 & $<0.05$ \\
\hline$\triangle \mathrm{BMI}$ & -0.269 & $<0.03$ \\
\hline \multicolumn{3}{|c|}{$\begin{array}{l}\text { Simple regression analysis was performed between the A1c index } \\
\text { and the baseline levels or changes of the indicated parameters } \\
\text { (overall subjects). The results are expressed as the mean } \pm \text { SD. }\end{array}$} \\
\hline
\end{tabular}

tomatic, therefore they may lack the sense that they have clinically significant disorders. Thus, a delay in diagnosis may occur. Nevertheless, sitagliptin $25-50 \mathrm{mg} /$ day monotherapy in these subjects was shown to be rather effective in reducing blood glucose levels (both HbA1c and FBG, see - Table 1) without any clinically significant adverse events on the kidney or liver. However, two subjects reported mild, potential (unproven) hypoglycemic events and one subject reported gastrointestinal complains. In the past years, our group has been investigating the safety and efficacy of new oral hypoglycemic drugs (e. g. DPP-4 inhibitors, SGLT-2 inhibitors) in newly diagnosed, drug naïve subjects of $\operatorname{T2DM}[9,11]$. In comparison to other drugs tested in identical settings, sitagliptin appears to have better tolerability profiles and low rates of adverse events. Although the numbers of the subjects in this study are small and the study duration is short, these results implicate that sitagliptin could be effectively and safely used as one of the first-line drugs for T2DM. BMI had a tendency to increase in the overall subjects ( $\triangleright$ Table 1) and significantly increased in good-responders ( $\triangleright$ Table 4 panel a). Significant elevations of UA, although still within normal range, were observed in all the groups ( $\triangleright$ Table 1, $\triangleright$ Table 4 panel a, b, c). Currently it is unclear whether the increased body weight and UA have any impact on the increased risk for cardiovascular disorders or gout. To this end, it is of note that good-responders had higher degrees of elevations of UA in comparison to poor-responders ( $\triangleright$ Fig. 2 panel c). Furthermore significant negative correlations were seen between the A1c index and the change of $(\Delta)$ UA in this group. This may support our previous hypothesis that elevated serum UA may enhance beta-cell functions, thereby resulting in better glycemic efficacy [14].

In analogy to other oral hypoglycemic drugs, the changes of $\mathrm{HbA} 1 \mathrm{c}$ with sitagliptin is proportional to the baseline $\mathrm{HbA} 1 \mathrm{c}$ levels ( $\triangleright$ Fig. 1a). However, FBG showed no such pattern ( $\triangleright$ Fig. 1b), suggesting that this drug could predominantly influence postprandial glucose levels. DPP-4 inhibitors including sitagliptin increases the active forms of GLP-1 and glucose-dependent insulinotropic polypeptide (GIP). These peptide hormones are known to enhance firstphase insulin secretion through cAMP and subsequent activation of Epac2A/Rap1 pathway in the pancreas [14-16]. Thus, those with high postprandial glucose levels may benefit from DPP-4 inhibitor therapy. Postprandial hyperglycemia has been associated with cardiovascular disorders (CVD) independent of HbA1c or FBG [17]. Increased oxidative stress has been proposed as a pathophysiologic mechanism for this [18]. Thus, sitagliptin may be useful for controlling postprandial glucose excursion, thereby reducing the risks for CVD.

Based on the baseline comparison analysis between good-responders and poor-responders ( $>$ Table 3 ), those with high levels of baseline $\mathrm{HbA} 1 \mathrm{c}$, and low BMI or atherogenic lipids including T-C and nonHDL-C were more responsive to sitagliptin. These characters may represent Asians. At the same time, since significant negative and positive correlations were seen between the A1c index and the baseline levels of CPR-index and T-C, respectively ( $\vee$ Table 2a), those who possess well preserved pancreatic beta-cell function and low $\mathrm{T}-\mathrm{C}$ could be more responsive to this drug. The patients in this study are mostly newly diagnosed patients with T2DM. Although their glycemic control is poor, their beta-cell functions (insulin secretory capacities) are probably still preserved. Thus, this fact could also be one reason why sitagliptin is suitable as one of the initial pharmacotherapies for T2DM.

\section{Effect of sitagliptin on beta-cell function and insulin sensitivity in relation to its glycemic efficacy}

DPP-4 inhibitors are known to augment beta-cell function [2,3], however, their effects on insulin resistance (sensitivity) remain elu- 
- Table 3 Baseline comparison of baseline levels of glycemic and non-glycemic parameters between good responders and poor responders treated with sitagliptin.

\begin{tabular}{|c|c|c|c|}
\hline & baseline & baseline & p-values \\
\hline age (years) & $54.3 \pm 13.7$ & $55.3 \pm 13.1$ & n.s. \\
\hline $\mathrm{F} / \mathrm{M}$ & $6 / 17$ & $2 / 21$ & n.s. \\
\hline A1c index & $-0.0357 \pm 0.0682$ & $-0.3562 \pm 0.1006$ & n.s. \\
\hline $\mathrm{UA}(\mathrm{mg} / \mathrm{dl})$ & $4.87 \pm 13.8$ & $5.12 \pm 1.41$ & n.s. \\
\hline U-UA/U-CRE & $0.488 \pm 0.113$ & $0.479 \pm 0.177$ & n.s. \\
\hline $\mathrm{FBG}(\mathrm{mg} / \mathrm{dl})$ & $234.2 \pm 56.4$ & $224.0 \pm 59.4$ & n.s. \\
\hline $\operatorname{HbA1c}(\%)$ & $9.85 \pm 2.06$ & $11.03 \pm 1.96$ & 0.054 \\
\hline insulin $(\mu \mathrm{U} / \mathrm{ml})$ & $7.30 \pm 4.71$ & $6.08 \pm 3.38$ & n.s. \\
\hline HOMA-R & $4.35 \pm 3.29$ & $3.14 \pm 1.74$ & n.s. \\
\hline HOMA-B & $16.64 \pm 12.39$ & $18.19 \pm 15.97$ & n.s. \\
\hline C-peptide (ng/ml) & $1.98 \pm 0.85$ & $2.09 \pm 0.88$ & n.s. \\
\hline 20/(C-pepidexFBG) & $0.0548 \pm 0.0291$ & $0.0549 \pm 0.0291$ & n.s. \\
\hline CPR-index & $0.886 \pm 0.409$ & $1.050 \pm 0.635$ & n.s. \\
\hline BMI & $24.76 \pm 4.52$ & $23.96 \pm 3.90$ & $<0.05$ \\
\hline $\mathrm{T}-\mathrm{C}(\mathrm{mg} / \mathrm{dl})$ & $234.4 \pm 42.6$ & $208.3 \pm 32.5$ & $<0.03$ \\
\hline TG (mg/dl) & $262.0 \pm 251.1$ & $158.3 \pm 110.1$ & 0.076 \\
\hline HDL-C (mg/dl) & $54.4 \pm 16.3$ & $54.0 \pm 14.2$ & n.s. \\
\hline $\mathrm{T}-\mathrm{C} / \mathrm{HDL}-\mathrm{C}$ & $4.529 \pm 1.143$ & $4.062 \pm 1.081$ & n.s. \\
\hline nonHDL-C (mg/dl) & $180.0 \pm 42.1$ & $154.3 \pm 34.8$ & $<0.03$ \\
\hline $\log (\mathrm{TG} / \mathrm{HDL}-\mathrm{C})$ & $0.563 \pm 0.380$ & $0.393 \pm 0.347$ & n.s. \\
\hline nonHDL-C/HDL-C & $3.529 \pm 1.143$ & $3.062 \pm 1.081$ & n.s. \\
\hline $\mathrm{LDL}-\mathrm{C}(\mathrm{mg} / \mathrm{dl})$ & $148.5 \pm 29.7$ & $133.7 \pm 29.9$ & n.s. \\
\hline
\end{tabular}

- Table 4 Changes of glycemic and non-glycemic parameters after 3 months treatment of sitagliptin in good-responders and poor-responders.

\begin{tabular}{|c|c|c|c|c|}
\hline panel a & baseline & 3 months & $\%$ changes & p-values \\
\hline age (years) & $55.3 \pm 13.1$ & & & \\
\hline $\mathrm{F} / \mathrm{M}$ & $2 / 21$ & & & \\
\hline A1c index & $-0.3562 \pm 0.1006$ & & & \\
\hline FBG (mg/dl) & $224.0 \pm 59.4$ & $148.6 \pm 57.1$ & -33.6 & $<0.00001$ \\
\hline HbA1c (\%) & $11.03 \pm 1.96$ & $7.00 \pm 1.32$ & -36.5 & $<0.00001$ \\
\hline insulin $(\mu \mathrm{U} / \mathrm{ml})$ & $6.08 \pm 3.38$ & $6.64 \pm 4.17$ & 9.2 & n.s. \\
\hline HOMA-R & $3.14 \pm 1.74$ & $2.20 \pm 1.35$ & -29.9 & $<0.03$ \\
\hline HOMA-B & $18.19 \pm 15.97$ & $42.95 \pm 49.1$ & 136.1 & $<0.004$ \\
\hline C-peptide (ng/ml) & $2.09 \pm 0.88$ & $2.18 \pm 0.96$ & 4.3 & n.s. \\
\hline 20/(C-pepide ×FBG) & $0.0549 \pm 0.0291$ & $0.0820 \pm 0.0453$ & 49.3 & $<0.003$ \\
\hline CPR-index & $1.050 \pm 0.635$ & $1.666 \pm 0.908$ & 58.6 & $<0.00001$ \\
\hline $\mathrm{T}-\mathrm{C}(\mathrm{mg} / \mathrm{dl})$ & $208.3 \pm 32.5$ & $197.2 \pm 36.4$ & -5.3 & 0.054 \\
\hline $\mathrm{TG}(\mathrm{mg} / \mathrm{dl})$ & $158.3 \pm 110.1$ & $145.8 \pm 131.1$ & -7.8 & n.s. \\
\hline $\mathrm{HDL}-\mathrm{C}(\mathrm{mg} / \mathrm{dl})$ & $54.0 \pm 14.2$ & $55.5 \pm 16.5$ & 2.7 & n.s. \\
\hline $\mathrm{T}-\mathrm{C} / \mathrm{HDL}-\mathrm{C}$ & $4.062 \pm 1.081$ & $3.710 \pm 0.853$ & -8.6 & $<0.02$ \\
\hline nonHDL-C (mg/dl) & $154.3 \pm 34.8$ & $141.6 \pm 30.1$ & -8.2 & $<0.03$ \\
\hline nonHDL-C/HDL-C & $3.062 \pm 1.081$ & $2.710 \pm 0.853$ & -11.4 & $<0.02$ \\
\hline LDL-C (mg/dl) & $133.7 \pm 29.9$ & $122.5 \pm 28.9$ & -8.3 & $<0.05$ \\
\hline $\mathrm{UA}(\mathrm{mg} / \mathrm{dl})$ & $5.12 \pm 1.41$ & $5.65 \pm 1.23$ & 10.3 & $<0.02$ \\
\hline BMI & $23.96 \pm 3.90$ & $24.47 \pm 4.11$ & 2.1 & $<0.02$ \\
\hline
\end{tabular}


- Table 4 Continued.

\begin{tabular}{|c|c|c|c|c|}
\hline panel b & baseline & 3 months & $\%$ changes & p-values \\
\hline age (years) & $54.3 \pm 13.7$ & & & \\
\hline$F / M$ & $6 / 17$ & & & \\
\hline A1c index & $-0.0357 \pm 0.0682$ & & & \\
\hline FBG (mg/dl) & $234.2 \pm 56.4$ & $243.0 \pm 72.8$ & $<3.7$ & n.s. \\
\hline HbA1c (\%) & $9.85 \pm 2.06$ & $9.51 \pm 2.15$ & -3.4 & $<0.03$ \\
\hline insulin $(\mu \mathrm{U} / \mathrm{ml})$ & $7.30 \pm 4.71$ & $7.75 \pm 5.34$ & 6.1 & n.s. \\
\hline HOMA-R & $4.35 \pm 3.29$ & $4.79 \pm 3.91$ & 10.1 & n.s. \\
\hline HOMA-B & $16.64 \pm 12.39$ & $17.60 \pm 12.72$ & 5.7 & n.s. \\
\hline C-peptide (ng/ml) & $1.98 \pm 0.85$ & $2.23 \pm 1.06$ & 12.6 & $<0.02$ \\
\hline 20/(C-pepide ×FBG) & $0.0548 \pm 0.0291$ & $0.0521 \pm 0.0327$ & -4.9 & n.s. \\
\hline CPR-index & $0.886 \pm 0.409$ & $0.964 \pm 0.442$ & 8.8 & n.s. \\
\hline $\mathrm{T}-\mathrm{C}(\mathrm{mg} / \mathrm{dl})$ & $234.4 \pm 42.6$ & $235.1 \pm 29.5$ & 0.2 & n.s. \\
\hline TG (mg/dl) & $262.0 \pm 251.1$ & $239.5 \pm 190.5$ & -8.5 & n.s. \\
\hline $\mathrm{HDL}-\mathrm{C}(\mathrm{mg} / \mathrm{dl})$ & $54.4 \pm 16.3$ & $55.6 \pm 16.5$ & 2.2 & n.s. \\
\hline $\mathrm{T}-\mathrm{C} / \mathrm{HDL}-\mathrm{C}$ & $4.529 \pm 1.143$ & $4.491 \pm 1.205$ & -0.8 & n.s. \\
\hline nonHDL-C (mg/dl) & $180.0 \pm 42.1$ & $179.5 \pm 32.9$ & -0.2 & n.s. \\
\hline nonHDL-C/HDL-C & $3.529 \pm 1.143$ & $3.491 \pm 1.205$ & -1.0 & n.s. \\
\hline LDL-C (mg/dl) & $148.5 \pm 29.7$ & $155.5 \pm 25.3$ & 4.7 & n.s. \\
\hline $\mathrm{UA}(\mathrm{mg} / \mathrm{dl})$ & $4.87 \pm 1.38$ & $5.20 \pm 1.54$ & 6.7 & $<0.04$ \\
\hline BMI & $24.76 \pm 4.52$ & $24.83 \pm 4.30$ & 0.2 & n.s. \\
\hline panel c & baseline & 3 months & \% changes & p-values \\
\hline age (years) & $56.5 \pm 11.6$ & & & \\
\hline$F / M$ & $7 / 16$ & & & \\
\hline A1c index & $-0.1542 \pm 0.0431$ & & & \\
\hline FBG (mg/dl) & $190.6 \pm 74.8$ & $180.7 \pm 67.5$ & -5.1 & n.s. \\
\hline HbA1c (\%) & $9.61 \pm 2.30$ & $8.15 \pm 2.14$ & -15.1 & $<0.00001$ \\
\hline insulin $(\mu \mathrm{U} / \mathrm{ml})$ & $6.60 \pm 4.51$ & $8.30 \pm 7.22$ & 25.7 & 0.078 \\
\hline HOMA-R & $3.02 \pm 2.37$ & $3.97 \pm 4.64$ & 31.4 & n.s. \\
\hline HOMA-B & $24.46 \pm 19.67$ & $30.39 \pm 23.30$ & 24.2 & n.s. \\
\hline C-peptide (ng/ml) & $1.85 \pm 0.98$ & $2.00 \pm 1.24$ & 8.1 & n.s. \\
\hline 20/(C-pepide × FBG) & $0.0834 \pm 0.0577$ & $0.0977 \pm 0.1015$ & 17.1 & n.s. \\
\hline CPR-index & $1.053 \pm 0.549$ & $1.194 \pm 0.691$ & 13.3 & n.s. \\
\hline $\mathrm{T}-\mathrm{C}(\mathrm{mg} / \mathrm{dl})$ & $235.8 \pm 44.4$ & $227.2 \pm 43.3$ & -3.6 & 0.073 \\
\hline TG (mg/dl) & $167.7 \pm 142.3$ & $168.0 \pm 102.2$ & 0.1 & n.s. \\
\hline $\mathrm{HDL}-\mathrm{C}(\mathrm{mg} / \mathrm{dl})$ & $58.9 \pm 14.5$ & $57.7 \pm 13.4$ & -2.0 & n.s. \\
\hline $\mathrm{T}-\mathrm{C} / \mathrm{HDL}-\mathrm{C}$ & $4.213 \pm 1.285$ & $4.141 \pm 1.273$ & -1.7 & n.s. \\
\hline nonHDL-C (mg/dl) & $176.9 \pm 44.7$ & $169.4 \pm 44.9$ & -4.2 & 0.084 \\
\hline nonHDL-C/HDL-C & $3.213 \pm 1.285$ & $3.141 \pm 1.273$ & -2.2 & n.s. \\
\hline LDL-C (mg/dl) & $150.3 \pm 36.9$ & $144.6 \pm 41.4$ & -3.7 & n.s. \\
\hline $\mathrm{UA}(\mathrm{mg} / \mathrm{dl})$ & $4.95 \pm 1.08$ & $5.45 \pm 1.45$ & 10.1 & $<0.03$ \\
\hline BMI & $25.27 \pm 4.69$ & $25.46 \pm 4.72$ & 0.7 & n.s. \\
\hline
\end{tabular}

sive. There are several conflicting data regarding this question [9. 19]. Insulin based indexes including HOMA-R and HOMA-B are widely used for the assessment of insulin resistance and beta-cell function, respectively [9]. However, the usage of these indexes might not be accurate in some patients (e.g. low BMI, decreased beta-cell cell function and high FBG, $[9,20])$. It has been reported that C-peptide and its related parameters [20/(C-peptide x FBG) and CPR-index] could be better predictors for the assessment of insulin sensitivity and beta-cell function, respectively $[9,20]$. With the simple regression analysis between the A1c index and changes 
these parameters in the overall subjects ( $\bullet$ Table $\mathbf{2 b}$ ), it was shown that modulation of insulin sensitivity/resistance and beta-cell function could determine the glycemic efficacy of sitagliptin. In goodresponders, these two distinct parameters resulted in ameliorated insulin resistance/sensitivity ( $\triangleright$ Table 4 panel a), while no changes in these parameters were noted in poor-responders ( $\triangleright$ Table 4 panel b). In order to consolidate the above findings, euglycemic clamp study in humans will be required in order to prove that sitagliptin has indeed beneficial effects on insulin sensitivity/resistance in those with good response with this drug. The beta-cell func-

a

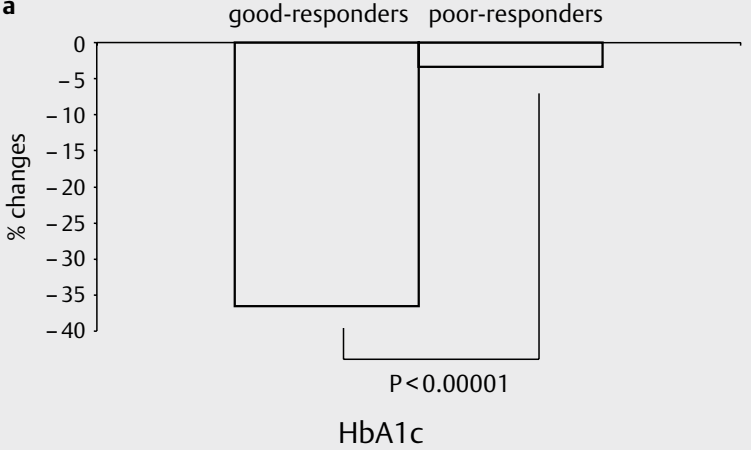

b

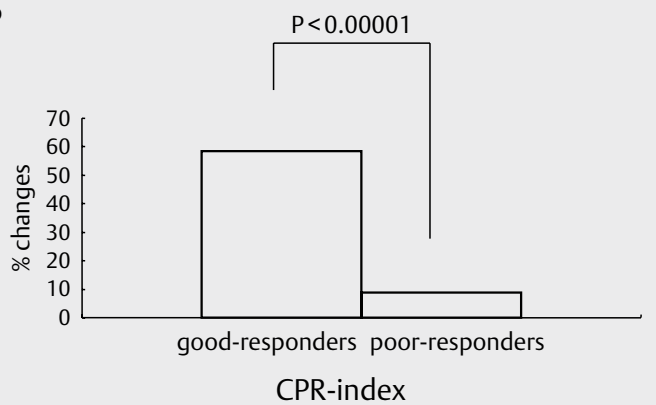

c

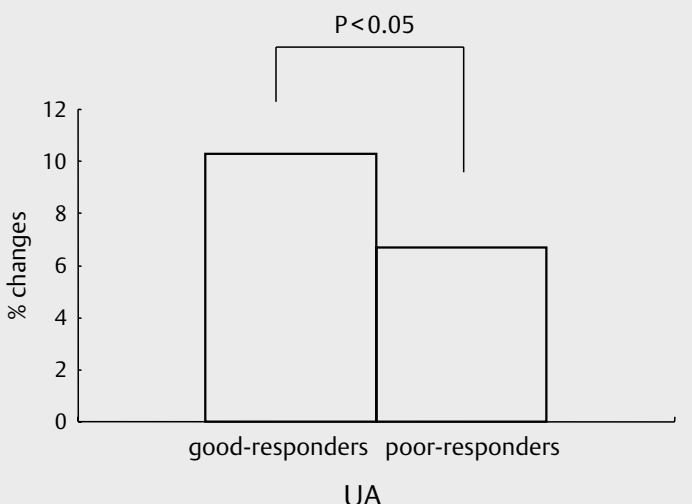

UA

- Fig. 2 Inter-group differences of the HbA1c, CPR-index and UA levels between good-responder and poor-responders. ANCOVA was performed to analyze the inter-group differences of the changes indicated parameters between good-responders and poor-responders. a HbA1c. b CPR-index. c UA. tion parameters (HOMA-B and CPR-index) were enhanced in goodresponders ( $\triangleright$ Table $\mathbf{1}$ and $\triangleright$ Table $\mathbf{4}$ panel a), while certain differences were seen in poor-responders (CPR-index significantly increased while HOMA-B had no changes, > Table 4 pane b). Using ANCOVA, beta-cell enhancing capacities based on CPR-index were much higher in good-responders than poor-responders ( $>$ Fig. $\mathbf{2}$, panel b). Taken together, sitagliptin could decrease insulin resistance as well as enhance beta-cell function especially in those with good response with this drug.

\section{Effect of sitagliptin on non-glycemic parameters in relation to its glycemic efficacy}

Effects of DPP-4 inhibitors on non-glycemic parameters such as lipids or body weight are controversial. In general, it is regarded as lipid or weight neutral [8]. In this present work, sitagliptin was shown to possess favorable effects on some lipid parameters including T-C, nonHDL-C, T-C/HDL and nonHDL-C/HLD-C in the overall subjects ( $\triangleright$ Table 1 ), and plus LDL-C in good-responders ( $\triangleright$ Table 4 panel a). By contrast, no effects on these parameters were noted in poor-responders ( $\triangleright$ Table $\mathbf{4}$ panel b). NonHDL-C may represent a more appropriate primary therapeutic target for diabetic dyslipidemia [21]. To this end, significant correlations between the A1c index and changes of atherogenic lipids including non HDL-C or LDL-C ( $\triangleright$ Table $\mathbf{2 b}$ ) indicate that certain link may exist between the glycemic efficacy and atherogenic lipids during sitagliptin treatment. Although this study does not compare sitagliptin with other drugs in this class, these beneficial effects of sitagliptin may have resulted in neutral cardiovascular outcomes in the TECOS study [22]. Thus the ability of sitagliptin to lower LDL-C in those with good response with this drug is an advantage of this drug. With respect to the effect of sitagliptin on body weight, conflicting date exist. Some report that sitagliptin can cause weight gain [23], while other report that this drug is weight neutral or can even decrease weight $[10,19]$. In this present work, BMI had a tendency to increase in the overall subjects and significantly increased in goodresponders ( $\vee$ Table $\mathbf{1 , 4}$ panel a). Further, the A1c index had a tendency to have negative correlations with the changes of $(\triangle) B M I$ in the overall subjects. No such correlations were noted in poor-responders ( $\triangleright$ Table 4 panel b). Thus, it is likely that body weight increase in those with good response with sitagliptin, possibly due to enhanced lipogenic (or anti-lipolytic) effects of insulin. It is of interest to undertake sub-analysis of the TECOS data according to the response with sitagliptin.

\section{The limitations and strengthens of the study}

Several limitations of this study may exist. The number of the subjects is small and the study duration is short. Furthermore, this study is not placebo-controlled. However one can assume that the observed changes were caused exclusively by sitagliptin based on the design of the study (monotherapy with drug naïve patients). Further randomized, double-blind, placebo-controlled longer period study with increased number of subjects will be necessary to strengthen the finding in this study. 


\section{Acknowledgements}

The author thanks Drs. Kenji Kawashima, Hideki Yamashita, Shugo Yonezawa, Takashi Suzuki and Takashi Nakamura for discussions and useful advice.

\section{Conflict of Interest}

The authors declare that no conflict of interests exists regarding this manuscript.

\section{References}

[1] Bosi E. American Diabetes Association. Pharmacologic approaches to glycemic treatment: Standards of Medical Care in Diabetes - 2020. Diabetes Care 2020; 43: S98-S110

[2] Ahrén B. DPP-4 Inhibition and the Path to Clinical Proof. Front Endocrinol (Lausanne) 2019; 10: 376. doi: 10.3389/fendo.2019.00376

[3] Neumiller J], Wood L, Campbell RK. Dipeptidyl peptidase-4 inhibitors for the treatment of type 2 diabetes mellitus. Pharmacotherapy 2010; 30: 463-484

[4] Bosi E. Time for testing incretin therapies in early type 1 diabetes? J Clin Endocrinol Metab 2010; 95: 2607-2609

[5] Davis $\mathrm{H}$, Jones Briscoe V, Dumbadze $\mathrm{S}$ et al. Using DPP-4 inhibitors to modulate beta cell function in type 1 diabetes and in the treatment of diabetic kidney disease. Expert Opin Investig Drugs 2019; 28: 377-388

[6] Lee M, Rhee MK. Sitagliptin for type 2 diabetes: A 2015 update. Expert Rev Cardiovasc Ther 2015; 13: 597-610

[7] Plosker GL. Sitagliptin: A review of its use in patients with type 2 diabetes mellitus. Drugs 2014; 74: 223-242

[8] Monami M, Lamanna C, Desideri CM et al. DPP-4 inhibitors and lipids: systematic review and meta-analysis. Adv Ther 2012; 29: 14-25

[9] Kutoh E, Hirate M, Wada A. Distinct glucose-lowering properties in good responders treated with sitagliptin and alogliptin. Int I Clin Pract 2015; 69: 1296-1302

[10] Daniele G, Tura A, Dardano A et al. Effects of treatment with metformin and/or sitagliptin on beta-cell function and insulin resistance in prediabetic women with previous gestational diabetes. Diabetes Obes Metab 2020; 22: 648-657

[11] Kutoh E, Wada A, Murayama T et al. Canagliflozin as an initial therapy in drug-naïve subjects with type 2 diabetes mellitus: A potential involvement of atherogenic lipids in its glycemic efficacy. Drugs R D 2017; $17: 313-320$
[12] Matthews DR, Hosker JP, Rudenski AS et al. Homeostasis model assessment: insulin resistance and beta-cell function from fasting plasma glucose and insulin concentrations in man. Diabetologia 1985; 28: $412-419$

[13] Amrhein V, Korner-Nievergelt F, Roth T. The earth is flat $(p>0.05)$ : Significance thresholds and the crisis of unreplicable research. Peer] 2017; 5: e3544

[14] Kutoh E, Wada A, Kuto AN et al. Regulation of serum uric acid with canagliflozin monotherapy in type 2 diabetes: A potential link between uric acid and pancreatic $\beta$-cell function. Int J Clin Pharmacol Ther 2019; 57: 590-595

[15] Eiki J, Yada T. Dynamics of plasma active GLP-1 versus insulin and glucose concentrations during GLP-1 infusion in rat model of postprandial hyperglycemia. Endocr J 2011; 58: 691-698

[16] Seino S, Shibasaki T, Minami K. Dynamics of insulin secretion and the clinical implications for obesity and diabetes. I Clin Invest 2011; 121: 2118-2125

[17] Meigs JB, Nathan DM, D’Agostino RB Sr et al. Fasting and postchallenge glycemia and cardiovascular disease risk: The Framingham Offspring Study. Diabetes Care 2002; 25: 1845-1850

[18] Ceriello A. Postprandial hyperglycemia and diabetes complications: Is it time to treat? Diabetes 2005; 54: 1-7

[19] Tajima N, Eiki Jl, Okamoto T et al. Factors associated with the glucose-lowering efficacy of sitagliptin in Japanese patients with type 2 diabetes mellitus: Pooled analysis of Japanese clinical trials. J Diabetes Investig 2019, doi:10.1111/jdi.13182

[20] Ohkura T, Shiochi H, Fujioka Y et al. 20/(fasting C-peptide × fasting plasma glucose) is a simple and effective index of insulin resistance in patients with type 2 diabetes mellitus: A preliminary report. Cardiovascular Diabetology 2013; 12: 21

[21] Kutoh E. Differential regulations of lipid profiles between Japanese responders and nonresponders treated with pioglitazone. Postgrad Med 2011; 123: 45-52

[22] Green JB, Bethel MA, Armstrong PW et al. TECOS study group. effect of sitagliptin on cardiovascular outcomes in type 2 diabetes. N Engl J Med 2015; 373: 232-242

[23] Kobayashi K, Yokoh H, Sato Y et al. SUCCESS Study Group. Efficacy and safety of the dipeptidyl peptidase-4 inhibitor sitagliptin compared with $\alpha$-glucosidase inhibitor in Japanese patients with type 2 diabetes inadequately controlled on sulfonylurea alone (SUCCESS-2): A multicenter, randomized, open-label, non-inferiority trial. Diabetes Obes Metab 2014; 16: 761-765 